\title{
Analysis of Static Flow Resistivity of a Modified Impedance Tube
}

\author{
J. Niresh ${ }^{1}$, S. Neelakrishnan 1 , S. Subha Rani' ${ }^{2}$, Siddharth Shrivastava1 \\ ${ }^{1}$ Department of Automobile Engineering, PSG College of Technology, Coimbatore, India \\ ${ }^{2}$ Department of Electronics \& Communication Engineering, PSG College of Technology, Coimbatore, India

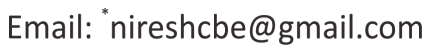

Received 11 March 2016; accepted 10 April 2016; published 18 July 2016

Copyright (C) 2016 by authors and Scientific Research Publishing Inc.

This work is licensed under the Creative Commons Attribution International License (CC BY).

http://creativecommons.org/licenses/by/4.0/

c) (i) Open Access

\begin{abstract}
The static flow resistivity is a fundamental parameter for measuring and classifying the sound absorption behavior of various types of materials. Several methods have been developed for measuring the static flow resistivity acoustically. Most of these methods cannot be implemented directly in the standard tubes which are widely used for measurements of sound absorption coefficients and impedance as defined in ISO 10534.2. The accuracy of the proposed method and the tube is verified through finite element analysis and the feasibility to determine the static flow resistivity is validated through experiments. It is validated that the accuracy of the proposed method is highly dependent on the position of the acoustic center of the measurement microphones and the accuracy can be enhanced by increasing the back cavity depth and/or decreasing the measurement frequency.
\end{abstract}

\section{Keywords}

Static Flow Resistivity, Impedance Tube, ISO 10534.2, Sound Absorption

\section{Introduction}

Sound absorbing materials are essential considerations in building acoustics and noise reduction in the environment. For determining sound absorption coefficient, impedance tube is used universally. The normal sound absorption coefficient and the surface impedance of a material are often measured by an impedance tube [1] [2]. These properties include complex characteristic impedance, complex propagation constant, and random incidence absorption coefficient. The properties can be determined theoretically using the empirical prediction [3] [4]. The mechanical impedance is obtained by dividing the applied force to the particle velocity. In addition,

"Corresponding author.

How to cite this paper: Niresh, J., Neelakrishnan, S., Rani, S.S. and Shrivastava, S. (2016) Analysis of Static Flow Resistivity of a Modified Impedance Tube. Circuits and Systems, 7, 2253-2261. http://dx.doi.org/10.4236/cs.2016.79196 
acoustical impedance is the applied pressure divided by volume velocity [5]. Flow resistivity is determined as the real part of the ratio between the pressure drop and the flow velocity through a layer of material of unit thickness [6]. The flow resistivity plays a major role in the calculation of acoustic properties of materials like propagation constant, sound absorption and characteristic impedance. The methods for measuring the flow resistivity can be classified as direct flow method [7] and acoustical method [8] [9]. In the direct flow measurement, the pressure drop across the specimen and the flow velocity through specimen are measured separately and the ration between them is calculated. In the acoustical methods, measurements are carried out using the impedance tube with the sound generating source at one end and terminating rigid body at the other end. Microphones are placed between these two ends. There are several acoustical methods that are normally carried out in impedance tubes with a loudspeaker and several microphones at low frequency. McIntosh et al. [10] proposed to measure the sound pressure at both sides of the test specimen, and divided the sound pressure drop by the flow velocity and the specimen thickness to calculate the static flow resistivity. Woodcock et al. [11] measured the propagation constant and the characteristic impedance of the material by adopting two-cavity method and then calculated the effective flow resistivity using the inverse equation of the Delany and Bazley empirical formulae [12]. Jiancheng Tao et al. [13] found out that a thicker specimen provides more stable flow resistivity and allows a higher measurement frequency.

In this paper, a new method is proposed that can be directly applied with an impedance tube. The implementation is verified to determine the static flow resistivity and design of impedance tube. The advantage of the proposed method is that a standard impedance tube can be used directly to measure the flow resistivity. Based on the finite element model of the impedance tube, the effects of several factors can be obtained, such as position of the microphones, depth of the back cavity, measurement frequency and thickness of the specimen. The performance of the proposed method is validated by conducting experiments.

\section{Theory}

Noise control is essential in vehicles that carry passengers to long distances as they are confined to the same closed environment for a long range of time. Automotive companies employ various noise control materials at different locations. Generally in a car, materials like polyester, nylon, composites of carbon and aramid fibers are used. The materials are mainly placed in interior fitments, safety facilities, tire reinforcement, and carpets. They are also used for sound and thermal insulation.

Sound absorbing materials are commonly used to soften the acoustic environment of a closed volume by reducing the amplitude of the reflected waves. Absorptive materials are generally resistive in nature, either fibrous, porous or in rather special cases reactive resonators. Most of these products provide some degree of absorption at nearly all frequencies (up to $2 \mathrm{kHz}$ ) and performance at low frequencies typically increases with increasing material thickness. The absorption ratio and transmission loss that represent sound reflection and penetrating capability of a sample material, usually considered as the most important acoustical properties, are measured by an impedance tube.

The performance of sound absorbing materials is evaluated by the sound absorption coefficient $(\alpha)$. The sound propagation in a standing wave duct is assumed as stationary plane waves with zero mean flow speed propagating in air. The complex acoustic pressure $p(x, t)$ and the particle velocity $v(x, t)$ of the medium are given in Equations (1) and (2) [14].

$$
\begin{gathered}
p(x, t)=A \mathrm{e}^{j(\omega t-k x)}+\mathrm{e}^{j(\omega t+k x)} \\
v(x, t)=\frac{1}{z_{0}}\left[A \mathrm{e}^{j(\omega t-k x)}-B \mathrm{e}^{j(\omega t+k x)}\right]
\end{gathered}
$$

where $A$ and $B$ are amplitudes of the incident and reflected waves, $\omega$ is the angular frequency, $k$ is the wave number, $z_{0}$ is the characteristic impedance of the air at $20^{\circ} \mathrm{C}$, and $\rho$ and $c$ are the air density and speed of sound in air respectively.

\section{Measurement Setup}

The impedance tube is designed according to the standard impedance tube design ISO 10534.2 as shown in Figure 1. Here three microphones are kept on the side of a test specimen and at other end rigid termination is 


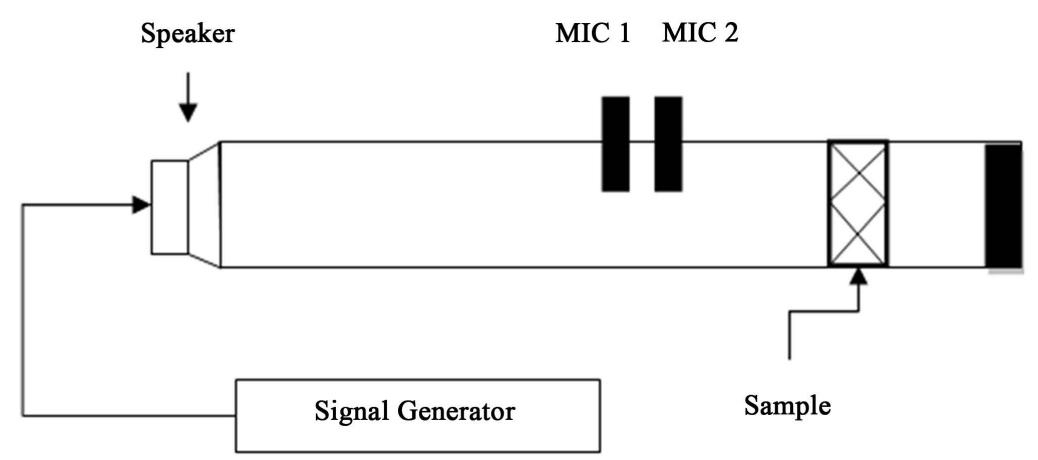

\section{Figure 1. Impedance tube diagram.}

present. The test specimen is considered to have a depth of $2 \mathrm{~L}$ and their back cavity depth is $\mathrm{L}$ which is the difference between surface of the specimen and the back termination. The loud speaker is placed at other end of the tube generating a broadband signal from $60 \mathrm{~Hz}$ to $1600 \mathrm{~Hz}$. The sample is placed at the end of the tube on the hard termination. Two BSWA type MPA416 microphones are implemented. Since in practical applications it is hard to generate tens of frequency, the minimum frequency is kept at $100 \mathrm{~Hz}$. Fortunately the static flow resistivity is not sensitive to frequency, when the measurement frequency is low [15]. The flow resistivity is acceptable when the frequency is few hundreds of $\mathrm{Hz}$.

The acoustic impedance at the front surface can be determined by

$$
Z_{c}=\rho c \frac{1+r}{1-r}
$$

where $\rho$ is the air density, $c$ is the speed of the sound and $r$ is the reflection coefficient

$$
r=\frac{H_{12}-H_{1}}{H_{r}-H_{12}} \mathrm{e}^{2 j k_{0} x_{1}}
$$

where $H_{12}=p_{2} / p_{1}$, Where $p$ is the measured sound pressure at microphones 1 and 2 respectively, $K_{0}$ is the wave number, it is defined as the $K_{0}=2 \pi f / c$, where $f$ is the frequency.

Similarly the acoustic impedance can be formulated by

$$
Z_{s}=Z_{m} \frac{Z_{L}+j Z_{m} \tan \left(2 k_{m} l\right)}{Z_{m}+j Z_{L} \tan \left(2 k_{m} l\right)}
$$

where $Z_{m}, k_{m}$ and $Z_{L}$ are characteristic impedance, propagation constant and the acoustic impedance at the back surface for the specimen. Accordingly the specimen is placed at the rigid termination $L=0$ and $\mathrm{Zl} \_$which is obtained as [16].

$$
k_{m}= \pm \frac{1}{2 l} \arctan \sqrt{\frac{Z_{L}}{Z_{s}}-\frac{Z_{s}^{\prime}\left(Z_{s}+Z_{L}\right)}{Z_{s}^{2}}}
$$

For porous material, flow resistivity can be calculated using [17]

$$
\sigma=-\lim _{\omega \rightarrow \infty}\left[\operatorname{lm}\left(Z_{m} k_{m}\right)\right]
$$

When the specimen thickness is rather small compared to the wavelength, it can be calculate as

$$
\Sigma=-\lim _{\omega \rightarrow \infty}\left\{\operatorname{lm}\left[\frac{Z_{L}-\frac{Z_{s}^{\prime}\left(Z_{s}+Z_{L}\right)}{Z_{s}}}{2 l}\right]\right\}
$$

In the proposed work the method involves (a) the sound absorption coefficient of porous material and nonporous material (b) the determination of static flow resistivity (c) the computation of the propagation constant 
and characteristic impedance, (d) Impedance measurements on the specimen when the back cavity is zero and at a random value L. It is compared to the Woodcock method and Jiancheng Tao et al method.

The modified cost impedance tube is designed as shown in Figure 2.

The impedance tube set up contains a signal source along with power amplifier section. The existing impedance tube signal characteristics is improved by modifying the signal source from generating monotone signals into one that generates white noise signals The main purpose of adding white noise is to provide a uniform reference frame in the time-frequency space [18]. Also white noise added signal permits frequencies analyze resolution of $6.25 \mathrm{~Hz}$ in a frequency domain of $125-10,000 \mathrm{~Hz}$. This high resolution is necessary for the evaluation of acoustic properties using impedance tube. The noise circuitry is designed by adding the signals generated from two similar signal generators, through a resistive network. The signal is amplified using a power amplifier circuit and fed into the impedance tube through a loud speaker.

Microphones that are placed inside the tube capture the incident signal and reflected signal from the sample. These signals are too weak to be transmitted to recording devices and hence preamplifiers are used to increase a microphone signal to line-level by providing stable gain while preventing induced noise that would otherwise distort the signal. A microphone preamplifier increases the 0 to 100 microvolt range level up by $70 \mathrm{~dB}$, to approximately 0 to 10 volts. A preamplifier is placed close to the microphone to reduce the effects of noise and interference. Most of the methods uses microphone, although sensors can be implemented a comprehensive review of techniques for measuring the acoustical response can be found it is important to have an accurate analytical expression for the response of a calibration object, and for this reason closed tubes are often employed, rather than cavities or open-ended tubes. The amplitude of the incident and reflected signals vary according to the sound absorption of the sample. Therefore by monitoring the amplitude variations of both signals and taking the ratio of it, the sound absorption coefficient of material is calculated. A digital storage oscilloscope, spectrum analyzer or a PC is used for storing and analyzing these signals.

\section{Simulations and Discussion}

In this proposed work, there are many factors that affect the measurement accuracy, such as the placement of the microphones, the rigidness of the termination and materials used for building the impedance tube. Controlling these factors in a real life experiment is not easy, and any small change in the experiment affects the outcome greatly. The extent of effects of such factors in this method is investigated through the finite element analysis of the impedance tube, which is done by using commercially available software COMSOL VERSION 5.0.

The experiment is conducted according to the ISO 10534.2. The body is composed of two parts connected by a screw mount as shown in Figure 3. A loudspeaker and three microphone ports are fixed on one side of the tube, and the right side is allocated for specimen placement. The measurement frequency range varies from 100 $\mathrm{Hz}-1600 \mathrm{~Hz}$. Measurements are made when the two microphones are placed at ports 1 and 3, and port 2 and port 3.

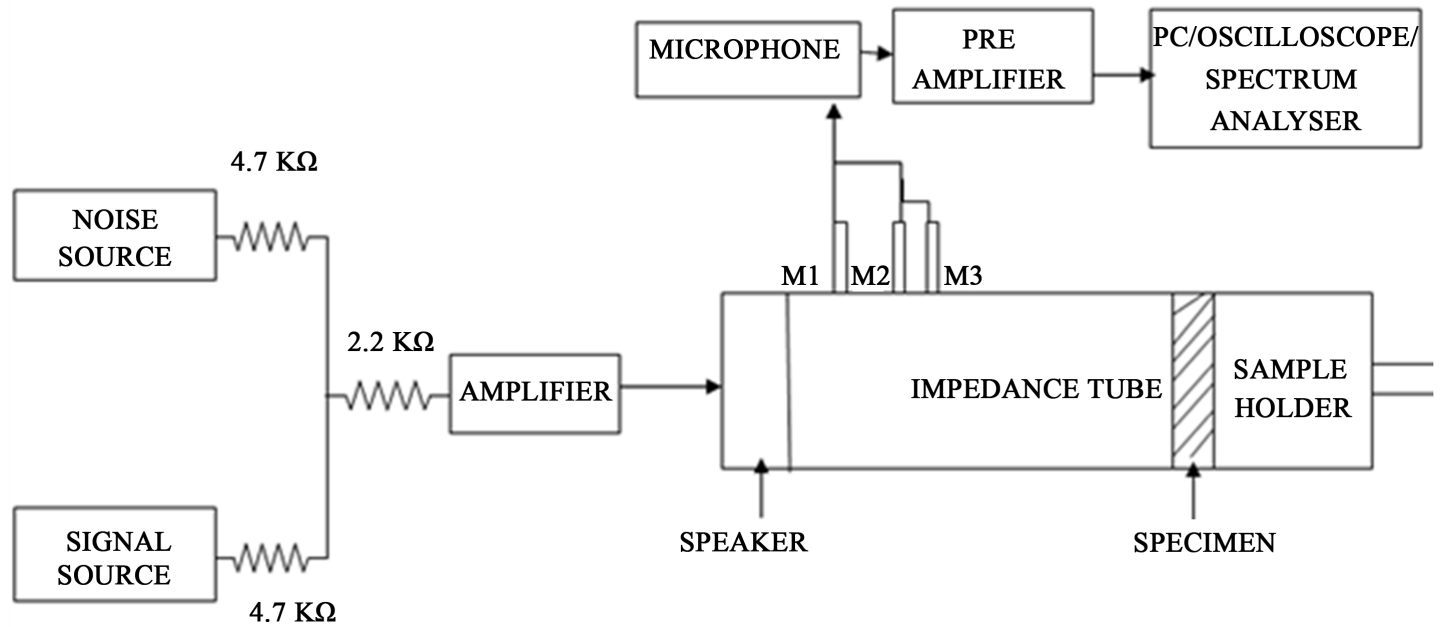

Figure 2. Block diagram of designed tube. 


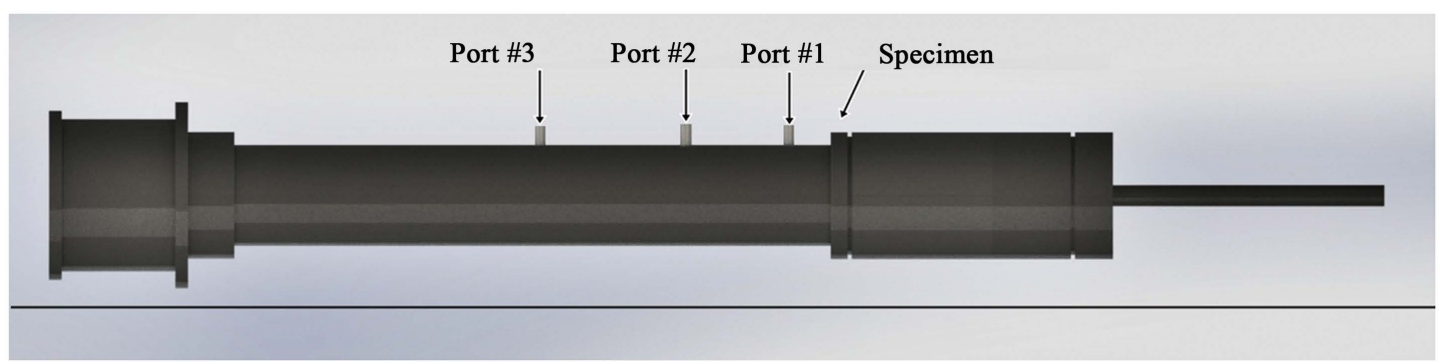

(a)

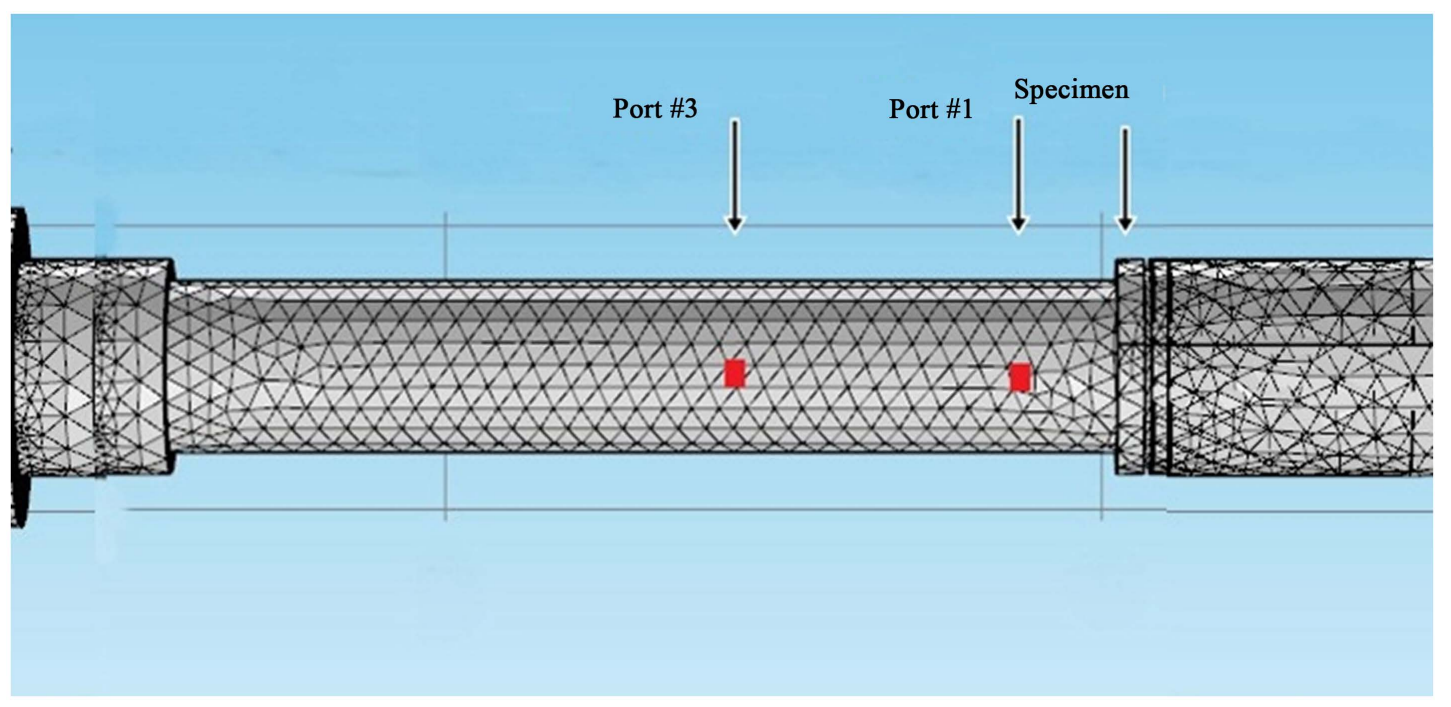

(b)

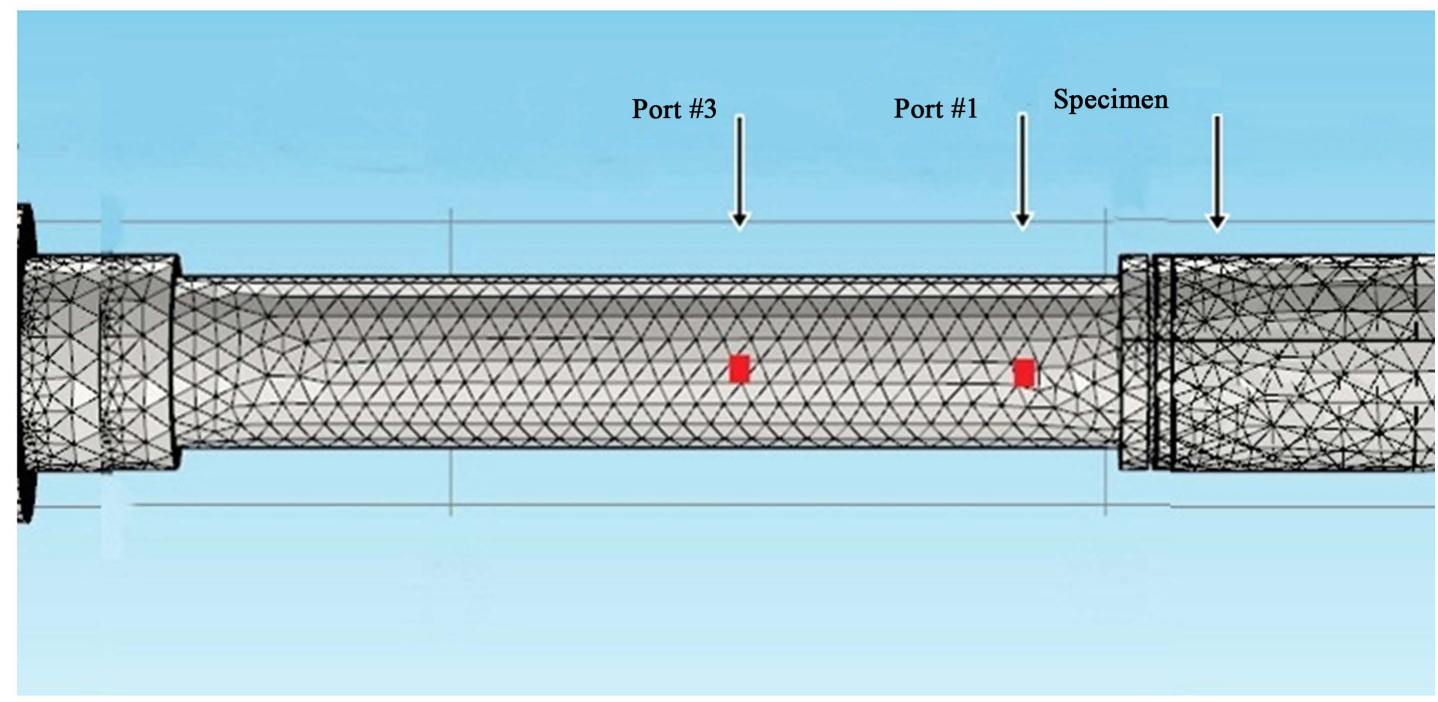

(c)

Figure 3. The standard impedance tube and the finite element analysis models: (a) a photo, (b) the finite element analysis model with the back cavity depth as $\mathrm{L} 1 / 40 \mathrm{~m}$, and (c) the finite element analysis model with the back cavity depth as L $1 / 40.1 \mathrm{~m}$.

In the finite element analysis, the measurement frequency, static flow resistivity and thickness of the material are the preset values. The particle velocity at the left termination end is set as $1.0 \mathrm{~m} / \mathrm{s}$ to generate the plane wave from the loudspeaker. The sound pressure at microphones is simulated by finite element model and the specific 
acoustic impedance on the front surface of the test material is determined at three instances: 1 ) When the back cavity depth is $0.02 \mathrm{~m}$; 2) When it is $0.10 \mathrm{~m}$ and 3 . When it is $0.15 \mathrm{~m}$. Then the propagation constant, the characteristic impedance, and the static flow resistivity can be obtained by using the Equations (5)-(7).

The calculated static flow resistivity and the preset values when the measurement frequency and the specimen thickness are preset as $100 \mathrm{~Hz}$ and $0.00 \mathrm{~m}$ are shown in Table 1. It can easily be seen from the calculated results that both Equations (7) and (8) are well within the preset parameters and the maximum error is $0.19 \%$. This shows that the proposed method can accurately measure the static flow resistivity. It should also be noted that the error of the predicted results from Equation (8) is larger than that predicted using Equation (7).

In the proposed method, the specific impedance on the specimen's front is measured when the back cavity depth is zero and $L$ to generate the propagation constant. We get different results with different back cavity depth $\mathrm{L}$ when the preset static flow resistivity, the measurement frequency, and the specimen thickness are $14,000 \mathrm{~N} / \mathrm{m}^{4}, 100 \mathrm{~Hz}$, and $0.02 \mathrm{~m}$, respectively. This is shown in Table 2 . It can be seen that there is an increase of accuracy with the increment of the cavity depth; however this improvement is limited because of the limited length of the right hand side of a standard impedance tube $(0.18 \mathrm{~m})$ and the thickness of the material.

The placement of the microphone is also an important factor affecting the outcome of acoustic measurements. The measurement and the errors due to movement of the acoustic center in four configurations are shown in Table 3. In the simulation, the movement of the acoustic center of the microphone is done by changing the point of measurement of sound pressure $0.01 \mathrm{~m}$ farther or closer to the test material. The flow resistivity is preset at $14,000 \mathrm{~N} / \mathrm{m}^{4}$, material thickness used is $0.02 \mathrm{~m}$, the measurement frequency is $100 \mathrm{~Hz}$ and the microphones are set at ports 1 and 3 .

It can be seen from Table 3 that even a $\pm 0.01 \mathrm{~m}$ movement of the microphone can cause large errors of up to $18.91 \%$, the maximum occurring when the two microphones are closest. It can also be seen that the results obtained by Equation (8) are less affected by the movement of microphones as compared to those calculated from Equation (7).

Table 1. The calculated static flow resistivity for the 0.02 -m-thick specimen at $100 \mathrm{~Hz}$.

\begin{tabular}{ccccc}
\hline Preset flow resistivity & Results from Equation (7) & \multicolumn{3}{c}{ Results from Equation (8) } \\
\hline Flow resistivity & Flow resistivity & Error & Flow resistivity & Error \\
$7000 \mathrm{~N} / \mathrm{m}^{4}$ & $7011 \mathrm{~N} / \mathrm{m}^{4}$ & 0.002 & $7015 \mathrm{~N} / \mathrm{m}^{4}$ & $0.19 \%$ \\
$14,000 \mathrm{~N} / \mathrm{m}^{4}$ & $14,009 \mathrm{~N} / \mathrm{m}^{4}$ & 0.001 & $14,011 \mathrm{~N} / \mathrm{m}^{4}$ & $0.11 \%$ \\
$28,000 \mathrm{~N} / \mathrm{m}^{4}$ & $27,988 \mathrm{~N} / \mathrm{m}^{4}$ & 0.001 & $28,004 \mathrm{~N} / \mathrm{m}^{4}$ & $0.16 \%$ \\
\hline
\end{tabular}

Table 2. The calculated static flow resistivity with different back cavity depths.

\begin{tabular}{ccccc}
\hline & Results from Equation (7) & \multicolumn{3}{c}{ Results from Equation (8) } \\
\hline Back cavity depth & Flow resistivity & Error & Flow resistivity & Error \\
$0.05 \mathrm{~m}$ & $14,007 \mathrm{~N} / \mathrm{m}^{4}$ & $0.05 \%$ & $14,016 \mathrm{~N} / \mathrm{m} 4$ & $0.13 \%$ \\
$0.10 \mathrm{~m}$ & $14,009 \mathrm{~N} / \mathrm{m}^{4}$ & $0.00 \%$ & $12,011 \mathrm{~N} / \mathrm{m} 4$ & $0.09 \%$ \\
$0.15 \mathrm{~m}$ & $14,002 \mathrm{~N} / \mathrm{m}^{4}$ & $0.00 \%$ & $14,010 \mathrm{~N} / \mathrm{m} 4$ & $0.08 \%$ \\
\hline
\end{tabular}

Table 3. The calculated static flow resistivity with different microphone positions.

\begin{tabular}{ccccc}
\hline & Results from Equation (7) & \multicolumn{3}{c}{ Results from Equation (8) } \\
\hline Microphone movement (Mic1 Mic3) & Flow resistivity & Error & Flow resistivity & Error \\
$(+0.01 \mathrm{~m},+0.01 \mathrm{~m})$ & $14,095 \mathrm{~N} / \mathrm{m}^{4}$ & $-7.69 \%$ & $14,100 \mathrm{~N} / \mathrm{m}^{4}$ & $-7.89 \%$ \\
$(-0.01 \mathrm{~m},-0.01 \mathrm{~m})$ & $16,085 \mathrm{~N} / \mathrm{m}^{4}$ & $9.33 \%$ & $16,088 \mathrm{~N} / \mathrm{m}^{4}$ & $9.97 \%$ \\
$(+0.01 \mathrm{~m},-0.01 \mathrm{~m})$ & $17,412 \mathrm{~N} / \mathrm{m}^{4}$ & $-13.74 \%$ & $17,497 \mathrm{~N} / \mathrm{m}^{4}$ & $-12.92 \%$ \\
$(-0.01 \mathrm{~m},+0.01 \mathrm{~m})$ & $18,234 \mathrm{~N} / \mathrm{m}^{4}$ & $18.91 \%$ & $18,215 \mathrm{~N} / \mathrm{m}^{4}$ & $18.47 \%$ \\
\hline
\end{tabular}


The calculated results with different frequencies and specimen thicknesses are presented in Table 4. The static flow resistivity is taken as $14,000 \mathrm{~N} / \mathrm{m}^{4}$, the back cavity depth is $0.00 \mathrm{~m}$ and the two microphones are placed at ports 2 and 3, as shown in Figure 3(a). It can be seen from Table 4 that, when the specimen thickness is fixed, the error increases with the increase in the frequency and the results from Equation (8) becomes less accurate.

\section{Experiments}

The experiment for the proposed model for determining the static flow resistivity and measurement of sound absorption co efficient for the customized impedance tube are conducted. The side length of circular cross section of the customized impedance tube is $0.17 \mathrm{~m}$, the frequency is around $100 \mathrm{~Hz}$. The space between the specimen and termination is $1.06 \mathrm{~m}$. Both porous and non-porous materials are used as test specimens for measuring using the customized impedance tube and standard impedance tube. The experimental setup with two $1 / 4$ inch microphone and a digital acquisition is shown in Figure 4.



Figure 4. The measured flow resistivity in modified tube for back cavity $0.5 \mathrm{~m}$ and $1.0 \mathrm{~m}$.

Table 4. The calculated static flow resistivity with different measurement frequencies and specimen thicknesses.

\begin{tabular}{cccccc}
\hline $\begin{array}{c}\text { Specimen } \\
\text { thickness }\end{array}$ & $\begin{array}{c}\text { Measurement } \\
\text { frequency }\end{array}$ & $\begin{array}{c}\text { Results from Equation (7) } \\
\text { Flow resistivity }\end{array}$ & Error & $\begin{array}{c}\text { Results from Equation (8) } \\
\text { Flow resistivity }\end{array}$ & Error \\
\hline \multirow{2}{*}{$0.04 \mathrm{~m}$} & $100 \mathrm{~Hz}$ & $14,009 \mathrm{~N} / \mathrm{m}^{4}$ & $-0.10 \%$ & $14,011 \mathrm{~N} / \mathrm{m}^{4}$ & $0.11 \%$ \\
& $200 \mathrm{~Hz}$ & $13,989 \mathrm{~N} / \mathrm{m}^{4}$ & $-0.10 \%$ & $14,028 \mathrm{~N} / \mathrm{m}^{4}$ & $0.32 \%$ \\
& $400 \mathrm{~Hz}$ & $13,975 \mathrm{~N} / \mathrm{m}^{4}$ & $-0.04 \%$ & $14,153 \mathrm{~N} / \mathrm{m}^{4}$ & $1.27 \%$ \\
& $800 \mathrm{~Hz}$ & $13,971 \mathrm{~N} / \mathrm{m}^{4}$ & $-0.18 \%$ & $14,530 \mathrm{~N} / \mathrm{m}^{4}$ & $5.25 \%$ \\
& $1600 \mathrm{~Hz}$ & $13,923 \mathrm{~N} / \mathrm{m}^{4}$ & $-0.73 \%$ & $16,842 \mathrm{~N} / \mathrm{m}^{4}$ & $24.02 \%$ \\
& $100 \mathrm{~Hz}$ & $14,006 \mathrm{~N} / \mathrm{m}^{4}$ & $-0.10 \%$ & $14,034 \mathrm{~N} / \mathrm{m}^{4}$ & $0.27 \%$ \\
& $200 \mathrm{~Hz}$ & $13,989 \mathrm{~N} / \mathrm{m}^{4}$ & $-0.10 \%$ & $14,114 \mathrm{~N} / \mathrm{m}^{4}$ & $1.03 \%$ \\
& $400 \mathrm{~Hz}$ & $13,981 \mathrm{~N} / \mathrm{m}^{4}$ & $-0.05 \%$ & $14,407 \mathrm{~N} / \mathrm{m}^{4}$ & $4.23 \%$ \\
& $800 \mathrm{~Hz}$ & $13,972 \mathrm{~N} / \mathrm{m}^{4}$ & $-0.18 \%$ & $14,192 \mathrm{~N} / \mathrm{m}^{4}$ & $18.27 \%$ \\
& $1600 \mathrm{~Hz}$ & $13,924 \mathrm{~N} / \mathrm{m}^{4}$ & $-0.73 \%$ & $24,324 \mathrm{~N} / \mathrm{m}^{4}$ & $86.21 \%$ \\
& $100 \mathrm{~Hz}$ & $13,991 \mathrm{~N} / \mathrm{m}^{4}$ & $-0.10 \%$ & $13,988 \mathrm{~N} / \mathrm{m}^{4}$ & $-0.02 \%$ \\
& $200 \mathrm{~Hz}$ & $13,992 \mathrm{~N} / \mathrm{m}^{4}$ & $-0.10 \%$ & $11,979 \mathrm{~N} / \mathrm{m}^{4}$ & $-0.13 \%$ \\
& $400 \mathrm{~Hz}$ & $13,989 \mathrm{~N} / \mathrm{m}^{4}$ & $-0.05 \%$ & $13,858 \mathrm{~N} / \mathrm{m}^{4}$ & $-1.60 \%$ \\
& $800 \mathrm{~Hz}$ & $13,974 \mathrm{~N} / \mathrm{m}^{4}$ & $-0.18 \%$ & $11,926 \mathrm{~N} / \mathrm{m}^{4}$ & $-18.12 \%$ \\
& $1600 \mathrm{~Hz}$ & $6,513 \mathrm{~N} / \mathrm{m}^{4}$ & $63.22 \%$ & $7650 \mathrm{~N} / \mathrm{m}^{4}$ & $-51.25 \%$ \\
\hline
\end{tabular}


For obtaining the static flow resistivity, the sound pressure has to be measured from the front side of the specimen on the rigid termination $\mathrm{La}$ and Lb respectively in $\mathrm{dB}$. The experiment is conducted with a test specimen in the both customized tube and a standard impedance tube. The measurement is made with the frequency range from $100 \mathrm{~Hz}$ to $1600 \mathrm{~Hz}$ which is shown in Table 4. The static flow resistivity can be obtained by using the Equation (7). The measurement of the frequency is presented in Figure 4. It is seen that thicker specimen is preferred for measurements because the results are more stable and the frequency range of measurement can be wider.

\section{Conclusion}

In this paper, the static flow resistivity is measured using a modified impedance tube. A standard tube is designed based on the simulation of finite element analysis of a practical impedance tube. It was found that even a small change in the movement of the acoustic centers of the microphones will result in large variations in the percentage of error. Also at lower measurement frequencies it is seen that the overall measurement error is low. The feasibility of the proposed method is validated through experiments, and it is found that a thicker specimen provides more stable flow resistivity and allows a higher measurement frequency.

\section{References}

[1] ISO Standard 10534-1, Acoustics Determination of Sound Absorption Coefficient and Impedance in Impedance Tube, Part 1: Method Using Standing Wave Ratio, 1996.

[2] ISO Standard 10534-2, Acoustics Determination of Sound Absorption Coefficient and Impedance in Impedance Tube, Part 2: Transfer Function Method, 1998.

[3] Katz, B.F.G. (2000) Method to Resolve Microphone and Sample Location Errors in the Two Microphone Duct Measurement Method. The Journal of the Acoustical Society of America, 108, 2231-2235. http://dx.doi.org/10.1121/1.1314318

[4] Yang, T.-L. (2003) The Semi Empirical and Empirical Models for Predicting Sound Absorption Coefficients for a Novel Porous Laminated Composite Material. Journal of Vibration and Control, 9, 1249-1263.

[5] Dalmont, J.P. (2001) Acoustic Impedance Measurement, Part I: A Review. Journal of Sound and Vibration, 243, 427439. http://dx.doi.org/10.1006/jsvi.2000.3428

[6] ISO 9053, Acoustics e Materials for Acoustical Applications e Determination of Airflow Resistance, International Organization for Standardization, 1998.

[7] ASTM C522e03, Standard Test Method for Airflow Resistance of Acoustical Materials, American Society for Testing and Materials, 2009.

[8] Ingard, K.U. and Dear, T.A. (1985) Measurement of Acoustic Flow Resistance. Journal of Sound and Vibration, 103, 567-572. http://dx.doi.org/10.1016/S0022-460X(85)80024-9

[9] Doutres, O., Salissou, Y., Atalla, N. and Panneton, R. (2010) Evaluation of the Acoustic and Non-Acoustic Properties of Sound Absorbing Materials Using a Three-Microphone Impedance Tube. Applied Acoustics, 71, 506-509. http://dx.doi.org/10.1016/j.apacoust.2010.01.007

[10] McIntosh, J.D., Zuroski, M.T. and Lambert, R.F. (1990) Standing Wave Apparatus for Measuring Fundamental Properties of Acoustic Materials in Air. The Journal of the Acoustical Society of America, 88, 1929-1938. http://dx.doi.org/10.1121/1.400216

[11] Woodcock, R. and Hodgson, M. (1992) Acoustic Methods for Determining the Effective Flow Resistivity of Fibrous Materials. Journal of Sound and Vibration, 153, 186-191. http://dx.doi.org/10.1016/0022-460X(92)90639-F

[12] Delany, M.E. and Bazley, E.N. (1971) Acoustical Properties of Fibrous Absorbent Materials. Applied Acoustics, 3, 105-116. http://dx.doi.org/10.1016/0003-682X(70)90031-9

[13] Tao, J.C., Wang, P., Qiu, X.J. and Pan, J. (2015) Static Flow Resistivity Measurements Based on the ISO 10534.2 Standard Impedance Tube. Building and Environment, 94, 853-858. http://dx.doi.org/10.1016/j.buildenv.2015.06.001

[14] Yaniv, S.L. (1973) Impedance Tube Measurement of Propagation Constant and Characteristic Impedance of Porous Materials. The Journal of the Acoustical Society of America, 54, 1138-1142. http://dx.doi.org/10.1121/1.1914360

[15] Ren, M. and Jacobsen, F. (1993) A Method of Measuring the Dynamic Flow Resistance and Reactance of Porous Materials. Applied Acoustics, 39, 256-276. http://dx.doi.org/10.1016/0003-682X(93)90010-4

[16] Kinsler, L.E., Frey, A.R., Coppens, A.B. and Sanders, J.V. (2000) Fundamentals of Acoustics. 4th Edition, John Wiley and Sons Inc., Hoboken. 
[17] Dragonetti, R., Ianniello, C. and Romano, R.A. (2011) Measurement of the Resistivity of Porous Materials with an Alternating Air-Flow Method. The Journal of the Acoustical Society of America, 129, 753-764. http://dx.doi.org/10.1121/1.3523433

[18] Bies, D.A. and Hansen, C.H. (2009) Engineering Noise Control: Theory and Practice. 4th Edition, CRC Press, Boca Raton, FL.

\section{Submit or recommend next manuscript to SCIRP and we will provide best service for you:}

Accepting pre-submission inquiries through Email, Facebook, LinkedIn, Twitter, etc.

A wide selection of journals (inclusive of 9 subjects, more than 200 journals)

Providing 24-hour high-quality service

User-friendly online submission system

Fair and swift peer-review system

Efficient typesetting and proofreading procedure

Display of the result of downloads and visits, as well as the number of cited articles

Maximum dissemination of your research work

Submit your manuscript at: http://papersubmission.scirp.org/ 